\title{
ANOMALI OVERREACTION HYPOTHESIS DI BURSA EFEK INDONESIA
}

\author{
Ika Septi Kurnia Anggraeni \\ Universitas Nahdlatulu Ulama Surakarta
}

\begin{abstract}
ABSTRAK
Penelitian ini melakukan pengujian terhadap overreaction hypothesis, dalam hipotesis ini disebutkan bahwa portofolio loser setelah perioda pengujian akan memiliki rata-rata abnormal return kumulatif yang lebih baik, sedangkan portofolio winner setelah perioda pengujian akan mengalami pembalikan return, dalam hal ini rata-rata abnormal return kumulatif return portofolio winner akan menunjukkan performance yang semakin memburuk.Fenomena pembalikan return ini dikenal dengan anomali winner-losser.

Penelitian ini dengan menggunakan data saham yang terdaftar dalam LQ45 selama perioda 2016-2018, penelitian ini menemukan fenomena pembalikan return secara random, fenomena pembalikan return pada setiap minggu ke 4 secara acak membuktikan bahwa overreaction hypothesis terbukti.Hal ini membuktokan adanya fenomena anomali winner losser di passar modal Indonesia selama perioda 2016-2018.

Keywords : overreaction hypothesis, contrarian strategy, market anomaly, portofolio Losser,portofolio winner
\end{abstract}

\section{ABSTRACT}

This research intends to analyze the existence of overreaction hypothesis. Which predicts that losser portofolio after subsequent periods will have a high performances of average cumulative abnormal return. Contrary, winner portofolio will have a low performance of average cumulative abnormal return after the ssubsequent priods. Mean reversals of retunr also familier with winner-losser anomaly.

This research using stock of listed on LQ45 during the periods of 2016-2018, this research found that the mean reversals of return have been identified in randomly after 4 weeks. Overreaction Hypothesis is still evidence in Indonesian Stock Market during the periods 20162018.

Keywords : overreaction hypothesis, contrarian strategy, market anomaly, lossers portofolios, winners portofolios

\section{PENDAHULUAN}

Perkembangan pasar modal saat ini mengalami perkembangan yang cukup pesat, meskipun berbagai event penting seperti misalnya kondisi politik Indonesia akan mempengaruhi kondisi pasar modal. Penelitian bidang keuangan sampai saat ipasaemperdebatkan tentang efisiensi pasar modal. Hipotesis Efisiensi Pasar Modal menyebutkan bahwa reaksi pasar sangat ditentukan informasi baru yang masuk ke pasar. Warninda dan
Asri (2002) menyebutka bahwa pasar yang efisien akan bereaksi secara cepat dan tepat terhadap informasi. Sehingga tidak memungkinkan memperoleh keuntungan di atas normal (abnormal return). Hipotesis efisiensi pasar oleh Fama (1970) dkategorikan menjadi 3 yaitu bentuk lemah, setengah kuat dan kuat. Hipotesis efisiensi pasar saat ini telah menjadi dalil, namun beberapa penelitian menyebutkan adanya anomali-anomali pasar. Salah satunya adalah anomali reaksi pasar berlebihan 
atau dikenal sebagai Overreaction Hypothesis.

Overreaction Hypothesis pertama kali diperkenalkan oleh DeBond dan Thaler (1985) yang menyebutkan bahwa saham-saham yang memiliki nilai performance negatif (losser) dan saham-saham yang memiliki performance positif (winner) akan mengalami pembalikan return (reversal) pada periode-periode berikutmya. Hasil penemuan ini yang kemudian masih menjadi perdebatan sampai saat ini, banyak peneliti yang mempercayai adanya anomali winnerlosser, atau anomali-anaomali pasar lainnya. namun sebagian masih mempercayai bahwa masih ada hipotesis efisiensi pasar

Perjalanan panjang mengenai penelitian Overreaction Hypothesis menghasilkan dua kriteria yaitu long term overreaction hypothesis dan short term overreaction hypothesis. Penelitian mengenai short term overreaction hypothesis salah satunya dilakukan oleh Norliali, Nassir dan Abidin (2010) dengan menggunakan data di pasar modal Malaysia, menemukan bahwa ada indikasi adanya pembalikan harga dan adanya strategi kontrarian di pasar modal Malaysia, strategi kontrarian menunjukkan bahwa terjadi fenomena pembalikan harga dan para investor mendapatkan keuntungan abnormal return dari peristiwa pembalikan harga tersebut.
Penelitian lain dilakukan oleh Ali, Ahmad dan Anusakumar (2011) melakukan pengujian overreaction hypothesis di pasar modal Malaysia dan menemukan adanya fenomena pembalikan return pada saham-saham yang memiliki performance negatif atau losser menjadi positif pada perioda berikutnya, sedangkan saham-saham yang memiliki perioda positif menjadi negatif pada perioda berikutnya. Investor dapat memperoleh keuntungan abnormal return dati fenomena pembalikan return ini. Penelitian short run overreaction hypothesis di Indonesia pernah dilakukan oleh Pasaribu (2011) dengan menggunakan data saham LQ45 dan perioda waktu 2003-2007 tidak menemukan fenomena pembalikan return dengan menggunakan periode formasi 3 bulaan n, 6 bulan dan periode secara anual.

Penelitian yang dilakukan Novisiantara, Masyithoh dan Setiawan (2017) dengan menggunakan data saham perusahaan manufaktur yang terdaftar di indeks saham LQ45, melakukan pengajuan overreaction hypothesis dengan menggunakan perioda pengamatan tahun 2014 dan 2015. Mereka ingin melihat apakah terjadinya fenomena pembalikan pada saat peristiwa pemilihan Presiden di Indonesia tahun 2014. Hasil penelitian menunjukkan bahwa tidak ditemukan adanya fenomena pembalikan return 
pada saham postofolio losser maupun winner selama perioda waktu tersebut.

Berdasarkan uraian di atas maka penulis akan melakukan penelitian terhadap saham-saham yang terdaftar pada indeks saham LQ45 selama perioda waktu 2016 sampai dengan tahun 2018.

Tinjauan Pustaka

1. Overreaction Hypothesis dan Pembalikan Harga

Fenomena pembalikan return yang kemudian dikenal sebagai Overreaction hypothesis pertama kali ditemukan oleh DeBond dan Thaler (1985). Penelitian mereka menemukan bahwa adanya fenomrna pembalikan return pada saham-saham yang awalnya memiliki tingkat performance rata-rata positif dan saham-saham yang memiliki tingkat performance sangat negatif. Para investor yang membeli sahamsaham losser akan memperoleh keuntungan abnormal return pada saat investor menjual saham tersebut pada perioda berikutnya.

Dissanaike (1997) melakukan penelitian overreaction menggunakan data 1000 perusahaan di London dengan perioda waktu 1975-1991. Hasil penelitian ini menemukan bahwa Overreaction Hypothesis sepenuhnya tidak bertentangan dengan hipotesis efisiensi pasar, karena pada penelitian ini Dissanaike menggunakan data 1000 perusahaan yang memiliki ukuran size besar. Dissanaike (20003) melakukan perbaikan terhadap penelitian yang dilakukan tahun (1997melak) penelitian sebelumnya hanya melakukan pengontrolan pada faktor size tetapi tidak memasukkan pengontrolan terhadap anomali winner-losser effect, Dissanaike (2003) menemukan bahwa faktor size dan anomali winner losser effect tidak saling berhubungan.

Sukmawati dan Hermawan (2003) dalam Suciningsih (2011) menyebutkan bahwa overreaction hypothesis merupakan suatu reaksi yang berlawanan dengan kondisi normal. Hasil penelitian mereka menemukan bahwa saham-saham yang memiliki kualitas saham losser akan memiliki tingkat keuntungan yang lebih tinggi dibandingkan tsaham-saham yang memiliki kualitas saham winner.

Ottemoesoe dan Malelak (2014) menyebutkan bahwa banyak peneliti yang menemukan fenomrna pembalikan return atau reaksi pasar berlebihan akan diikuti oleh fenomena pembalikan harga yang menunjukkan perilaku koreksi yang menunjukkan fenomena reaksi pasar berlebihan. Hasil penelitian mereka dengan menggunakan data di negara Asia Tenggara termasuk Indonesia menunjukkan adanya fenomena pembalikan return tersebut pada setiap negara.

2. Short Term Overreaction (Overreaction Jangka Pendek) 
Hasil-hasil penelitian mengenai overreaction hypothesis telah menghasilkan dua fenomena pada perida pengamatan yang digunakan dalam penelitian yaitu short term overreaction hypothesis dan long term overreaction hypothesis. Pasaribu (2011) menyebutkan bahwa literatur keuangan substantif secara aktual mengidentifikasi 2 fenomena yang cukup berbeda, keduanya disebut overreaction effect. Pertama para peneliti mengisolasi fenomena jangka pendek yang muncul dari keterkejutan investor pada berita baik (buruk) perusahaan yang menghasilkan overshooting temporer pada nilai keseimbangan harga saham perusahaan yang terkena pengaruh.

Penelitian-penelitian short run overreaction yang dilakukan di Indonesia antara lain dilakukan oleh Heryana (2016) dengan menggunakan perioda pengamatan tahun 2011 sampai dengan 2013, data yang digunakan adalkah saham-saham yang terdaftar dalam indeks saham LQ45. Hasil penelitian menunjukkan bahwa terjadi pembalikan harga pada bulan Oktober2011, Februari 2012 dan Desember 2012. Terjadinya fenomena pembalikan saham diakibatkan oleh adanya perilaku overreaction dari para investor.

Pasaribu (2011) menggunakan perioda pengamatan 2003-2007 dengan menggunakan data saham yang terdaftar pada indeks LQ45, hasil penelitian menunjukkan bahwa adanya penerapan strategi kontrarian selama pieroda waktu tersebut, dimana investor memperoleh abnormal return yang tinggi pada saat terjadi fenomena pembalikan return tersebut.

Metode Penelitian

Penelitian ini dilakukan menggunakan data perusahaan-perusahaan yang terdaftar pada Indeks LQ45 di Bursa Efek indonesia selama perioda waktu 2016 sampai dengan 2018. Obyek dari penelitian ini adalah price reversal dari kedua portofolio saham losser dan portofolio saham winner yang ditunjukkan oleh CAR dan ACAR masing-masing portofolio pada perioda pengujian dan perioda formasi mingguan.

Data yang digunakan adalah data sekunder yang diambil pada IDX melalui websiteyahoo finance dan Bursa Efek Indonesia.Penelitian ini menggunakan metoda purposive sampling yaitu pengambilan sampel yang sesuai dengan kriteria yang akan digunakan dalam penelitian ini. Kriteria-kriteria tersebut antara lain:

1. Saham-saham perusahaan yang terdaftar dalam indeks LQ45 selama periode 2016-2018.

2. Perusahaan tersebut merupakan saham aktif yang konsisten melakukan transaksi selama perioda waktu 2016-2018. 
3. Data yang digunakan adalah data harian selama perioda waktu 2016-2018.

4. Untuk saham yang termasuk dalam kategori winner dilihat dari kecenderungan return yang positif selama perioda formasi

5. Untuk saham yang termasuk dalam kategori losser dilihat dari kecenderungan return negatif selama perioda formasi.

Definisi Variabel Operasional :

1. CAR Portofolio saham Losser : adalah portofolio saham yang memiliki tingkat abnormal return terendah $35 \%$ dari seluruh saham.

2. CAR Portofolio saham Winner : adalah portofolio saham yang memiliki tingkat abnormal return teretinggi 35\% dari seluruh saham.

3. c. ACAR portofolio Losser :Rata-rata kumulatif abnormal return portofolio losser yang diperoleh dengan menghitung kumulatif return dibagi dengan perioda pengujian $(\mathrm{Z})$

4. ACAR portofolio Winner :Ratarata kumulatif abnormal return portofolio Winner yang diperoleh dengan menghitung kumulatif return dibagi dengan perioda pengujian $(\mathrm{Z})$

\section{Pengujian eksistensi anomaly winner-loser (Overreaction Hypothesis)}

Overreaction Hypothesis akan terbukti jika mempunyai syarat sebagai berikut Untuk portofolio Losser H1a: CAR FP > CAR TP ACAR FP > ACAR TP

Artinya portofolio Losser akan mempunyai tingkat keuntungan anormal yang semakin membaik dibandingkan perioda sebelumya.

Untuk portofolio Winner $\mathrm{H} 1 \mathrm{~b}=\mathrm{CAR}$ TP $>$ CAR FP

\section{ACAR TP > ACAR FP}

Artinya portofolio winner akan mempunyai tingkat keuntungan abnormal yang lebih rendah dibandingkan perioda sebelumya.

Untuk melihat adanya fenomena overreaction menggunakan metoda yang pernah dilakukan oleh Debond dan Thaaler (1985) yaitu dimana H1c : ACAR LOSSER - ACAR WINNER > 0

Karena terjadi fenomena pembalikan harga saham dimana CAR portofolio Losser lebih baik dibandingkan perioda sebelumnya dan demikian sebaliknya untuk portofolio Winner, maka overreaction hypothesis akan terbukti apabila rata-rata kumulatif abnormal return portofolio Losser mampu mengungguli rata-rata kumulatif abnormal return portofolio Winner. Pengujian hipotesis pertama dan kedua 
dilakukan dengan menggunakan paired samples t-test,

Hasil Penelitian

Tahapan berikutnya dalam penelitian ini adalah melakukan pembentukan portofolio sebagai berikut:Hasil pengujian hipotesis 1 yang menyebutkan adanya fenomena pembalikan return antara portofolio Losser dan poertofolio Winner dan adanya perbedaan positif antara abnormal return rata-rata portofolio losser dan winner ditunjukkan oleh tabel berikut ini :

Tabel 1

CAR Portofolio Losser

\begin{tabular}{|ccccc|}
\hline & \multicolumn{5}{c|}{ Formation Period } \\
Test Period & 2 & 3 & 4 & 5 \\
\hline$-0,0310$ & $-0,0352$ & $-0,0226$ & 0,0655 & 0,0567 \\
$(-6.152)$ & $(-2.207)$ & $(-5,944)$ & $(12,27)$ & $(2.107)$ \\
& & & & \\
\hline
\end{tabular}

Sumber data diolah

Tabel 1 menunjukkan kinerja performance kumulatif abnormal return portofolio losser (Cumulative Abnormal Return). Salah satu ciri terjadinya fenomena pembalikan return atau mean reversal adalah setelah perioda pengujian portofolio losser menunjukkan kinerja yang lebih baik dibandingkan sebelumnya atau dengan kata lain $\mathrm{CAR}_{\text {TestPeriod - }}$ $\mathrm{CAR}_{\text {FormationPeriod }}>0$

Dari Tabel 1 dapat kita lihat bahwa pada minggu ke 2 dan ke 3 portofolio losser masih menunjukkan nilai negatif, dan kemudian menjadi positif di minggu ke 4. Pada minggu ke
5 kumulatif abnormal return portofolio menunjukkan nilai negatif. Hal ini berati fenomena pembalikan return positif hanya terjadi pada minggu ke 4 untuk postofolio saham Losser.Hal ini merupakan sinyal bagi investor untuk membeli portofolio saham Losser, karena mereka akan mendapatkan tingkat keuntungan abnormal return yang cukup tinggi.

Tabel 2

CAR Portofolio Winner

\begin{tabular}{|cccccc|}
\hline \multicolumn{3}{|c|}{ Test Period } & \multicolumn{4}{c|}{ Formation Period } \\
& & 2 & 3 & 4 & 5 \\
\hline 0,7833 & $-0,219$ & $-0,054$ & $-0,172$ & $-0,211$ \\
$(3,14)$ & $(-5.85)$ & $(-12.49)$ & $(-4,74)$ & $(-4.83)$ \\
\hline
\end{tabular}

Sumber data diolah

Tabel ke2 menunjukkan kinerja portofolio Winner, salah satu ciri overreaction hypothesis terbukti apabila kinerja portofolio winner mengalami mean reversal return menjadi negatif, atau preformance kumulati abnormal return portofolio winner memiliki kinerja yang semakin memburuk.

Dari tabel 2 dapat kita lihat bahwa sejak minggu ke 2 sampai dengan minggu ke 5 postofolio Winner memiliki performace kumulatif abnormal return yang negatif setelah perioda pengujian, Hal ini menunjukkan adanya fenomena pembalikan return pada portofolio winner yang semakin menurun, hal ini dapat dijadikan sinyal oleh investor untuk mengetahui bahwa mereka tidak 
akan memperoleh keuntungan dari pembelian saham-saham portofolio Winner.

Tabel 3

ACAR OSSER - ACAR WINNER

\begin{tabular}{|rrrrr|}
\hline & & 2 & 3 & 4 \\
\hline & $-0,639$ & $-0,467$ & 0,8451 & $-0,53$ \\
& $(-5.48)$ & $(-5.93)$ & $(7.983)$ & $(-$ \\
$4,99)$ & & & & \\
\hline
\end{tabular}

Sumber data diolah

Tabel 3 menunjukkan perbedaan rata-rata kumulatif abnormal return portofolio Losser dan portofolio Winner, fenomena pembalikan return akan terbukti apabila performance portofolio Losser mampu mengungguli portofolio winner atau dengan kata lain:

ACARPORTOFOLIOLOSSER

ACAR PORTOFOLIOWINNER $>0$

Dari Tabel 3 dapat kita lihat bahwa performance portofolio Losser hanya mampu mengungguli performance portofolio saham Winner di minggu ke 4, untuk minggu ke 2, 3 dan 5 performance portofolio saham Losser tidak mampu mengungguli performance portofolio saham winner.

Dari keseluruhan tabe; dapat kita simpulkan bahwa fenomena overreaction hypothesis hanya terjadi di minggu ke 4. Karena memenuhi syarat Overreaction Hypothesis sebagai berikut:

\section{CAR TESTPERIODLOSSER}

CAR $_{\text {FORMATIONPERIODLOSSER }}>0$

CAR TESTPERIODWINNER

CAR FORMATIONPERIOD WINNER $<0$
ACARPORTOFOLIOLOSSER

ACARPORTOFOLIOWINNER $>0$

Dari keseluruhan tabel dapat disimpulkan bahwa terajadi fenomena pembalikan return hanya terjadi pada minggu ke4.

Dari keseluruhan hasil penelitian dapat disimpulkan bahwa fenomena pembaliakan return (mean reversal return) yang konsisten hanya terjadi pada portofolio saham Winner sejak minggu ke 2. Sedangkan fenomena pembalikan return pada postofolio Losser hanya terjadi pada minggu ke 4. Sedangkan performance portofolio saham Losser hanya mampu mengungguli portofolio saham Winner pada minggu ke 4. Hal ini menunjukkan bahwa fenomena Overreaction Hypothesis selama perioda waktu 2016 sampai 2018 tidak konsisten terjadi.

Simpulan

Hasil penelitian ini menunjukkan gejala overreaction hypothesis meskipun menggunakan short run dengan perioda waktu dari tahun 2016-2018. Hal ini berati membuktikan adanya anomali winner-losser di Pasar Modal Indonesia. Fenomena pembalikan harga antara portofolio saham Losser dan portofolio saham WWinner menunjukkan bahwa overreaction hypothesis terbukti setelah perioda pengujia 
Daftar Pustaka

Ali,.Ahmad,. \& Shangkan (2011). Stock Market Overreaction and trading Volatility Evidence From malaysia. Asean Academy of management. Journal of Accounting \& Finance. AAMJAF. Vol 7. 103119.

Damel, K,D,.Hirsleiferand A,.Subrahmanyam (1998) Investor Psycology and Security market Underreaction and Overreaction. Journal of finance 53. 1839-1885.

Debond, Werner F.M. dan R. Thaler (1985), Does the stockmarket overreact? Journal Of Finance. Vol 40. 793-897.

Debond, Werner F.M. dan R. Thaler (1987), Further Evidence on Investor Overreaction and Stockmarket seasonality.Journal Of Finance. Vol 42. 557-581.

Dissanaike,G,.(1997) Does the Size Effect Explain the UK. WinnerLosser Effect?. Journal Of Bussiness Finance \& Accounting. 29(1) \& (2). 139154.

Fama, E.F. (1991) Efficient Capital market II. The Journal Of Finance. Vol 45. No 5. December.pp. 1575-1617.

Heryana, Tony (2016) Analisis Pembalikan Harga Saham di Indonesia Berbasis Overreaction Hypothesis, Ukuran Perusahaan, Likuiditas Saham, dan Bid Ask Spread. JRAK vol 4, No 3 (125-146).

Jogiyanto,.(2003). Teori portofolio dan Analisis Investasi.BPFE UGM. Yogyakarta.
Jones,C.P.(2000) Investment Analysis and management. $\quad 7^{\text {th }}$ editionNew York. John Willey \& Sons Inc.

Lobe,S,. \& Rieks, J,. (2011)Stock Market Overreaction on the Kuala lumpur Stock Exchange. Capital Market Review.4. 2132.

Novisiantara, Ignasius Doddy, Siti Masyithoh, \& Ledy Setyawati,. (2017) Analisis Overreaction Pada Harga Saham Manufaktur. Jurnal Manajemen. Volume 9(1).(31-37)

Ottemoesoe, Ridhotama Santi Darsih \& Malelak, Mariana Ing, (2011). .Fenomena Reaksi Berlebihan atau Overreaction pada Transaksi Saham di Asia Tenggara. Proceeding FMI 6. Medan.

Pasaribu, Rowland Bismark Fernando (2011) Anomali Overreaction di Bursa Efek Indonesia (Case Study of LQ 45 Stocks). Jurnal Ekonomu dan Bisnis. (87-115)

Suciningtias, Siti Aisyah,.(2011) Gejala Overreaction yang tergabung pada saham-saham yang tergabung dalam Jakarta Islamic Indeks di Bursa Efek jakarta. EKOBIS. 12. No 1. Januari. 58-76.

Sukmawati, dan Daniel Hermawan (2002) . Overreact Hypothesis and Price Earning ratio Anomaly saham-saham sektor manufaktur di Bursa Efek Jakarta. Jurnal Riset Akuntansi. Manajemen dan Ekonomi. Vol 2. No.1 57-76.

Zarowin,P,.(1990). Seasonality and Stock market Overreaction. Journal of Finance and Quantitative Analysis. 25. 113125. 